\title{
Power Burst Facility/Boron Neutron Capture Therapy Program for Cancer Treatment \\ Volume 4, No. 7
}

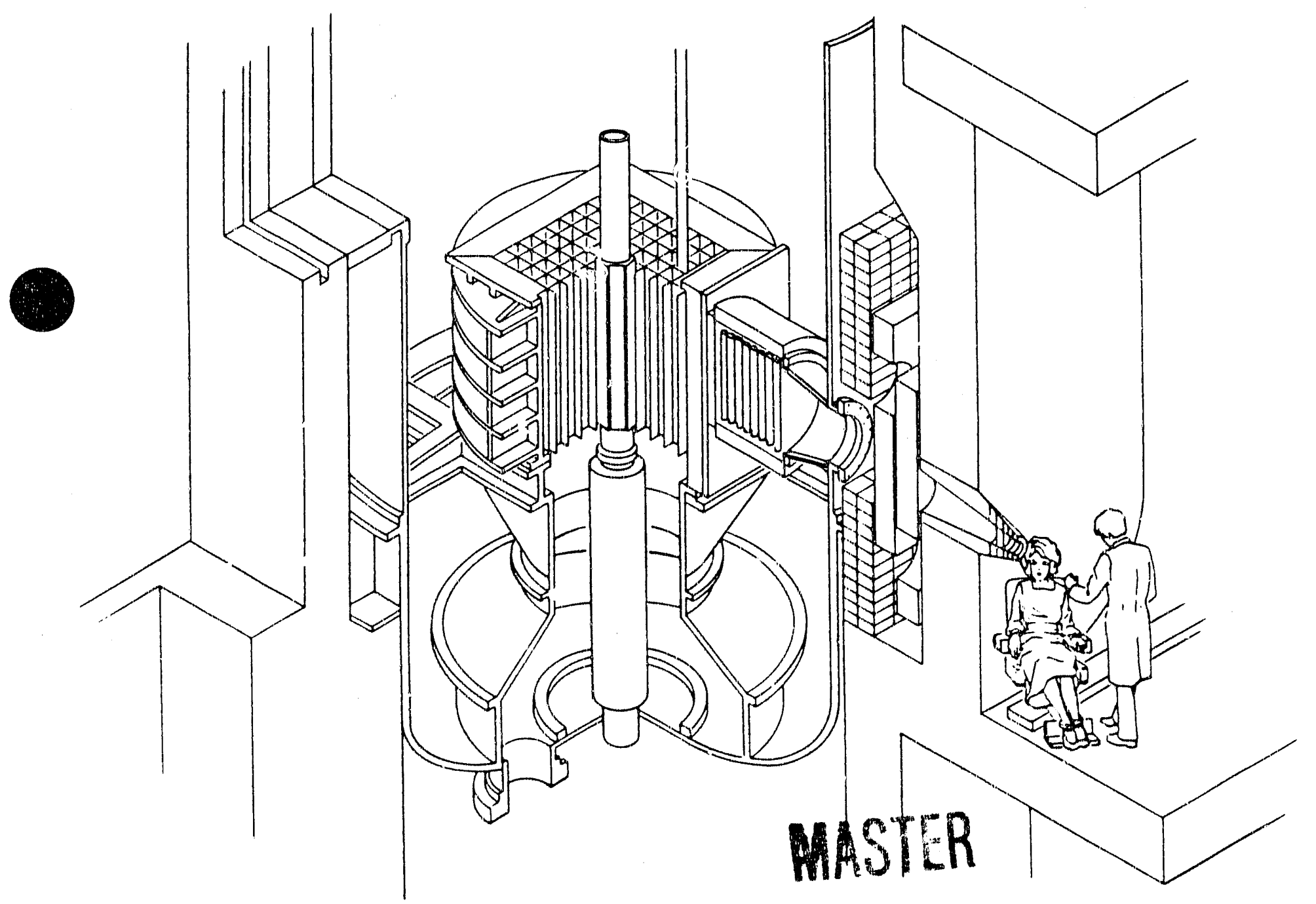

\section{Bulletin}

Prepared for the U.S. Department of Energy under DOE Contract No. DE.AC07-76ID01570 


\section{DISCLAIMER}

This book was prepared as an account of work sponsored by an agency of the United States Government. Neither the United States Government nor any agency thereof. nor any of their employees, makes any warranty, express or implied, or assumes any logal liability or responsibdity for the accuracy, completeness, or usefulness of any information, apparatus, product or process disclosed, or represents that its use would not infringe privately owned rights. Raferences herein to any specific commercial product, process, or service by trade name, trademark, mianufacturer, or otherwise, does not necessarily constitute or imply its endorsement, recommendation, of favoring by the United States Government or any agency thereof. The views and opinions of authors expressed herein do not necessarily state or reflect those of the United States Government or any agency thereof. 


\section{PBF/BNCT PROGRAM}

\section{MONTHLY BULLETIN}

\section{Principal Investigator's Highlights}

Highlights of the PBF/BNCT Program during July 1990 include progress within the areas of:

1. Project 1: Supporting Technology Development

Task 1: Gross Boron Analys is in Tissue, 8lood, and Urine - Over 500 samples from studies at Washington State University (WSU) (Project 2) were analyzed. Possible use of the inductively coupled plasma-mass spectrometer for boron analys is under evaluation.

Task 2: Analytical Methodologies Development for BSH (Borocaptate Sodium) Purity Determination - No reportable progress this month.

Task 4: Boron Microscopic (subcellular) Analytical Development No reportable progress this month.

Task 5: Noninvasive Boron Quantitative Determination Pharmacokinetic studies on BSH with two normal dogs were performed using magnetic resonance spectroscopy correlated with blood and tissue samples. Results are pending.

Task 6: Dosimetry - This task remains on hold because of cont inued unavailability of the Brookhaven Medical Research Reactor (BMRR).

Task 7: Analytical Radiation Transport and Interaction Modeling for BNCT - Extension of the University of Utah contract will now allow completion of modifications to the Alpha-1 graphics package for dose prediction. Software validation (for treatment planning software) underway using magnetic resonance images of the dog-head phantom. 
2. Project 2: Large Animal Model Studies - Several dogs with spontaneously-occurring brain tumors were entered into the terminal, pharmacokinetic study. BMRR downtime prevented additional treatment. Dogs previously entered into the program and normal tissue-tolerance studies continue to be followed.

3. Project 5: Neutron Source and Facility Preparation - Design and analysis work on the Power Burst Facility (PBF) modifications continue. Patient safety requirements are being researched.

4. Core A: Administration and Common Support - Dr. Gavin's (WSU) request to expand the canine brain-tumor study at Brookhaven National Laboratory (BNL) was disapproved by BNL citing the Department of Energy, Health and Environmental Research Advisory Committee (DOE-HERAC) report. In any event, BMRR remains unavailable. PBF/BNCT Program participants met with European BNCT researchers at WSU to discuss collaboration in dog studies.

5. Core B: PBF Operations - Safety, training, and preventive maintenance activities continue.

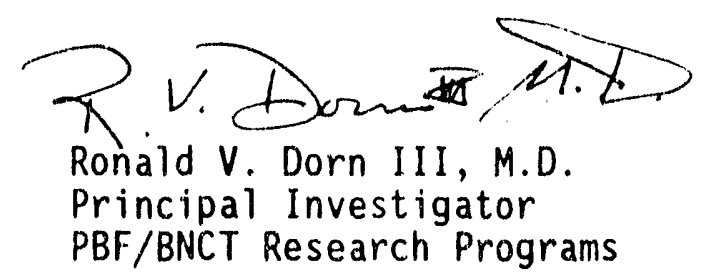


EGG-BNCT-8777

Vol. 4, No. 7

July, 1990

\section{ACRONYMS}

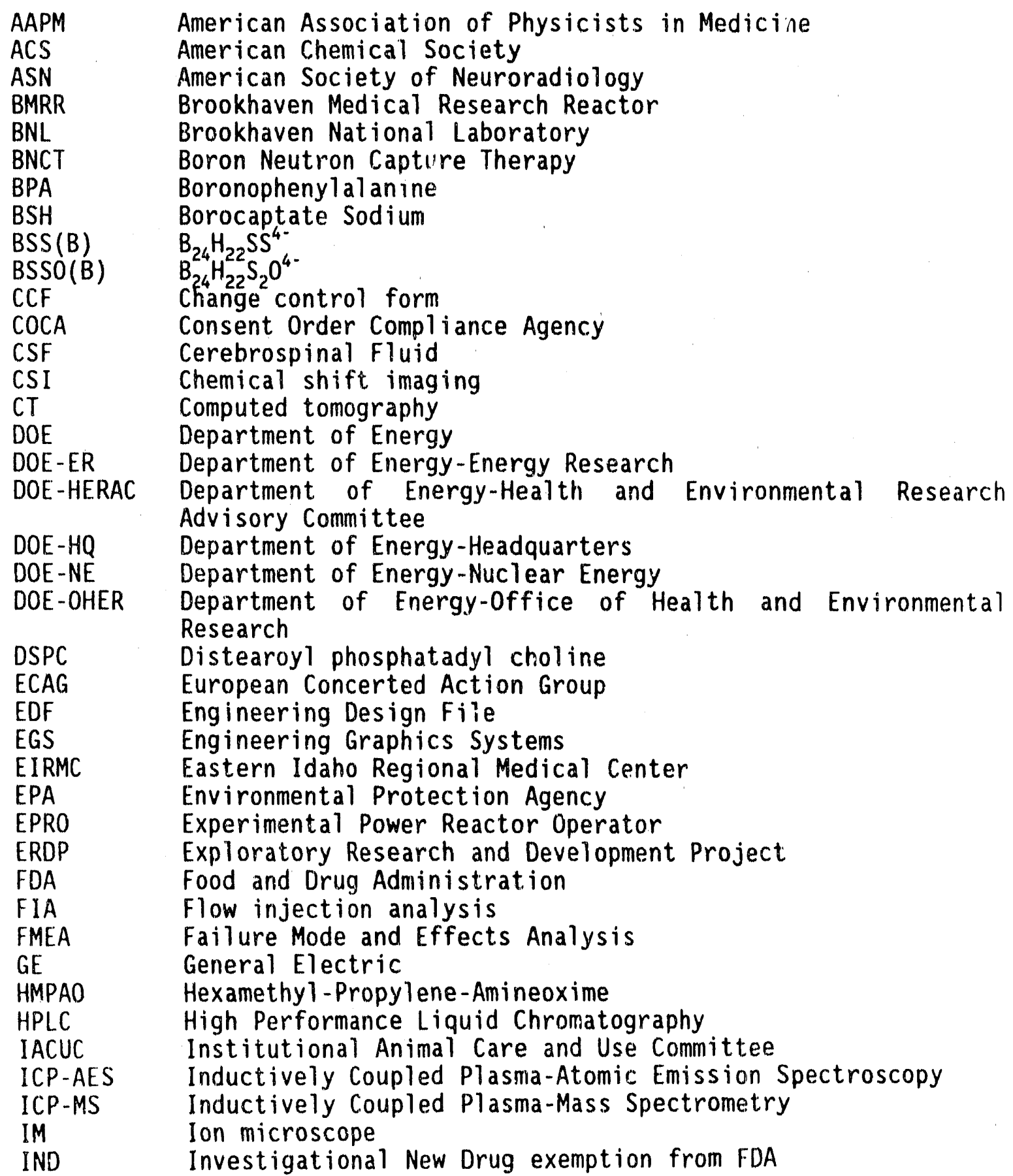


EGG-BNCT-8777

Vol. 4, No. 7

JuTy, 1990

\begin{tabular}{|c|c|}
\hline INEL & Idaho National Engineering Laboratory \\
\hline INPO & Institute of Nuclear Plant Operations \\
\hline ISU & Idaho State University \\
\hline IV & Intravenous \\
\hline KURRI & Kyoto University Reactor Research Institute \\
\hline LOFT/OECD & $\begin{array}{l}\text { Loss-of-Fluid Test/Organization of Economic Cooperation anc } \\
\text { Development }\end{array}$ \\
\hline MIT & Massachusetts Institute of Technology \\
\hline MR & Magnetic resonance \\
\hline MRI & Magnetic resonance imaging \\
\hline MRS & Magnetic resonance spectroscopy \\
\hline NCAR & National Center for Atmospheric Research \\
\hline NCI & National Cancer Institute \\
\hline NCS & Network computing system \\
\hline NDE & New Device Exemption (FDA) \\
\hline NESHAP & National Emission Standards for Hazardous Air Pollutants \\
\hline NIST & National Institute of Science and Technology \\
\hline NMR & Nuclear magnetic resonance \\
\hline NWI & Northwest Imaging \\
\hline OCT & A low-temperature adhesive \\
\hline OHSU & Oregon Health Sciences University \\
\hline ORAU & Oak Ridge Associated Universities \\
\hline ORNL & Oak Ridge National Laboratory \\
\hline PBF & Power Bürst Facility \\
\hline PDARS & Patient Data Acquisition and Retrieval System \\
\hline PET & Position Emission Tomography \\
\hline PMT & Photo multiplier tube \\
\hline POM & Plant operating manual \\
\hline RAP & Requirements Awareness Program \\
\hline RBE & Relative Biological Effectiveness \\
\hline RESL & Radiological and Environmental Sciences Laboratory \\
\hline RF & Radiofrequency \\
\hline SAR & Safety Analysis Report \\
\hline SDD & System Design Description \\
\hline SIMS & Secondary Ion Mass Spectrometry \\
\hline TLD & Thermoluminescent dosimeter \\
\hline TTAF & Test Train Assembly Area Facility \\
\hline UCSF & University of California San Francisco \\
\hline Uofu & University of Utah \\
\hline USDA & United States Department of Agriculture \\
\hline WSU & Washington State University \\
\hline
\end{tabular}




\section{PROJECT 1: SUPPORTING TECHNOLOGY DEVELOPMENT}

\section{Task 1: Gross Boron Analysis in Tissue, Blood, and Urine}

A total of 166 samples from dogs in the Washington State University (WSU) study (Project 2) were received for boron analysis during the morth. The total number of samples, including the actual samples, microfiltrations of blood serums, and $Q A / Q C$ samples awaiting preparation and analysis, is approximately 730. Approximately 328 samples have been prepped and await analysis, approximately 575 samples have been prepared for analysis, and over 500 samples were analyzed by inductively coupled plasma-atomic emission spectroscopy (ICP-AES) during July.

Analysis by ICP-AES slowed again this month because of ARL -3410 instrument downtime near the end of the month. ARL field service has been contacted and should be here on July 30 to address the problem.

Work was initiated to evaluate the boron analysis utility of the ICP-mass spectrometer (MS), located in the Idaho National Engineering Laboratory's (INEL) Environmental Chemistry Laboratory. Boron detection with this instrument appears to be quite sensitive. Not surprisingly, initial tests have been plagued with problems due to boron contamination. When the contamination problem is solved, this instrument should provide accurate analysis at very low solution boron levels.

\section{Task 2: Analytical Methodologies for BSH (Borocaptate Sodium) Purity Determination}

No reportable progress this month.

Task 3: Analytical Methodologies Development for Active Form Identification

This task is presently unfunded.

Task 4: Boron Microscopic (Subcellular) Analytical Development

No reportable progress this month. 
EGG-BNCT -8777

Vol. 4, No. 7

July, 1990

\section{Task 5: Noninvasive Boron Quantification Determination}

Pharmacokinetic Studies: A time study was conducted at Northwest Imaging (NWI) using two normal dogs (28 and $68 \mathrm{lbs})$. Both blood and tissue samples were taken in conjunction with the spectroscopy data over a time span of approximately four hours following start of intravenous infusion of borocaptate sodium $\left(\mathrm{Na}_{2} \mathrm{~B}_{12} \mathrm{H}_{11} \mathrm{SH}\right.$ or $\left.\mathrm{BSH}\right)$. Blood and tissue sample ICP-AES analyses results are not yet available. Figure 1 shows the spectroscopy data normalized to the peak spectrum ared value for each animal.

The spectra areas consist of the total boron signal coming from the whole dog head (nose to part of the neck) and are not localized to any one tissue area. Although the elimination rates appear similar, the data involves a limited sampling, and any inference of elimination rates must be deferred until more experiments are performed.

Software Development: New imaging protocols to improve spatial resolution and reduce signal arquisition time were installed at NWI without difficulty, but have not been tested. Preliminary software testing will use the Eastern Idaho Regional Medical Center's (EIRMC) magnetic resonance imaging (MRI) system (without boron imaging capability) since the boron imaging hardware has been moved to NWI.

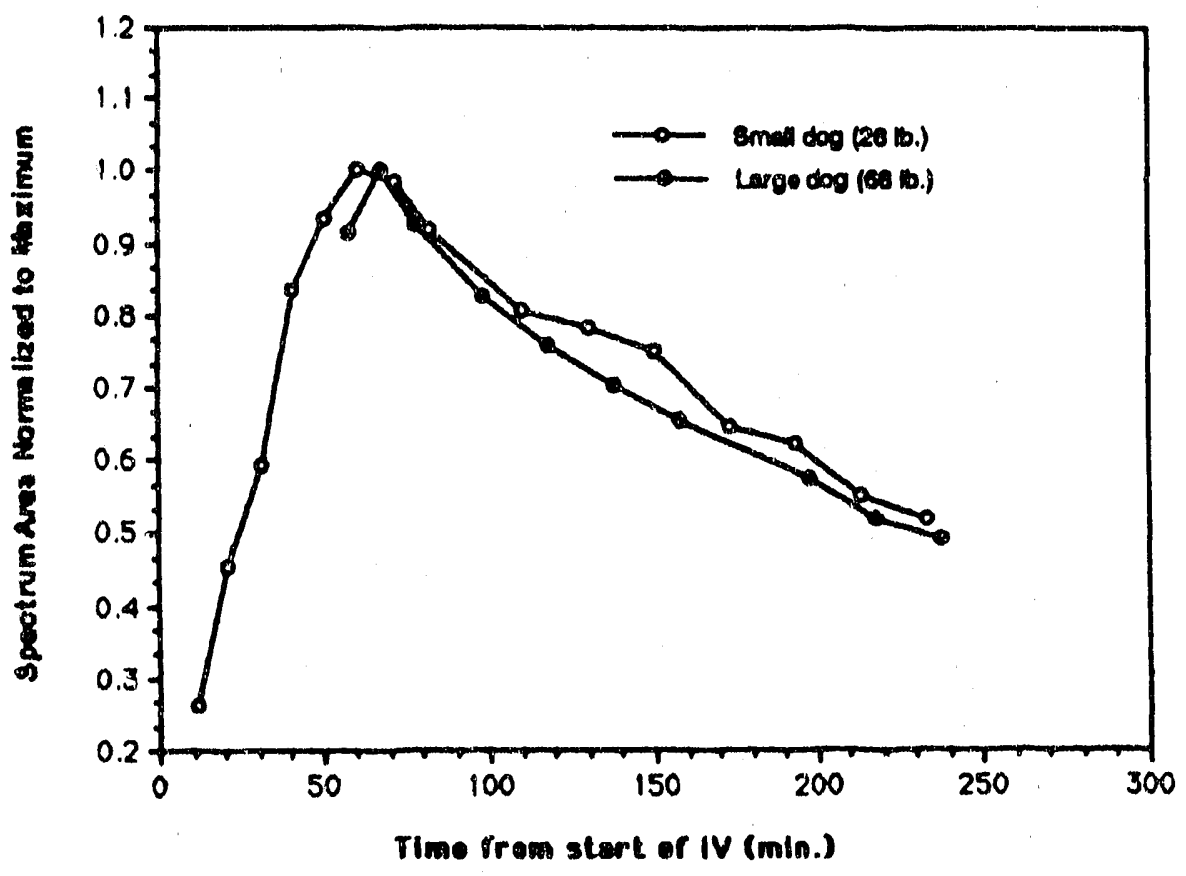

Figure 1. Comparison of elimination rates for BSH. 
EGG-BNCT -8777

Vol. 4 , No. 7

July, 1990

\section{Task 6: Dosimetry}

Dosimetry, in support of the large animal irradiation studies (Project 2), is still on hold pending Department of Energy (DOE) approval for the installation of shielding inside the animal irradiation room and resolution of the cooling water problem at the Brookhaven Medical Research Reactor (BMRR).

PIN diode, fast-neutron dosimeter neutron energy response measurement is tentatively scheduled for the latter part of August. PIN diode evaluation is a collaborative effort with Ohio State University, Brookhaven National Laboratory (BNL), and the INEL. Dr. Sharad Saraf, who initiated these measurements while at BNL, will take time from his new assignment at Thomas Jefferson Hospital in Philadelphia, PA to complete the assessment. The INEL role in this project is to provide an absolute measurement of the neutron fluence to which the PIN diodes are exposed during the assessments. The INEL fission chamber used to obtain the fluence has been calibrated at the National Institute of Science and Technology and shipped to Ohio State University.

\section{Task 7: Analytical Radiation Transport and Interaction Modeling for BNCT}

\section{Iask 7A; Analytical Methods Development}

Graphics Development: PBF/BNCT Program participants met with University of Utah (UofU) principals in Salt Lake City on July 26-27 to discuss a few final technical details and schedule software delivery. The contract extension to complete the BNCT geometric reconstruction software package has been signed. This obligates UofU to complete modifications to the Alpha-1 graphics package for dose prediction.

Radiation Transport Module: Coding development and improvement for the Monte Carlo module of the patient treatment planning system continued.

Software Validation: The EIRMC MRI machine was used to make a complete set of images of the lucite, dog-head phantom. These images will be used in a validation process for the patient treatment planning software. The geometry of the phantom will be reconstructed, using the Alpha-1 algorithm, and a radiation transport calculation will be performed for this phantom in the BMRR beam. Calculated radiation fields will be compared with data from flux-wire and gamma dosimeter measurements. The images for the phantom are of very high quality, with all flux-wire locations clearly showing (Figure 2). 
EGG-BNCT -8777

Vol. 4, No. 7

July, 1990

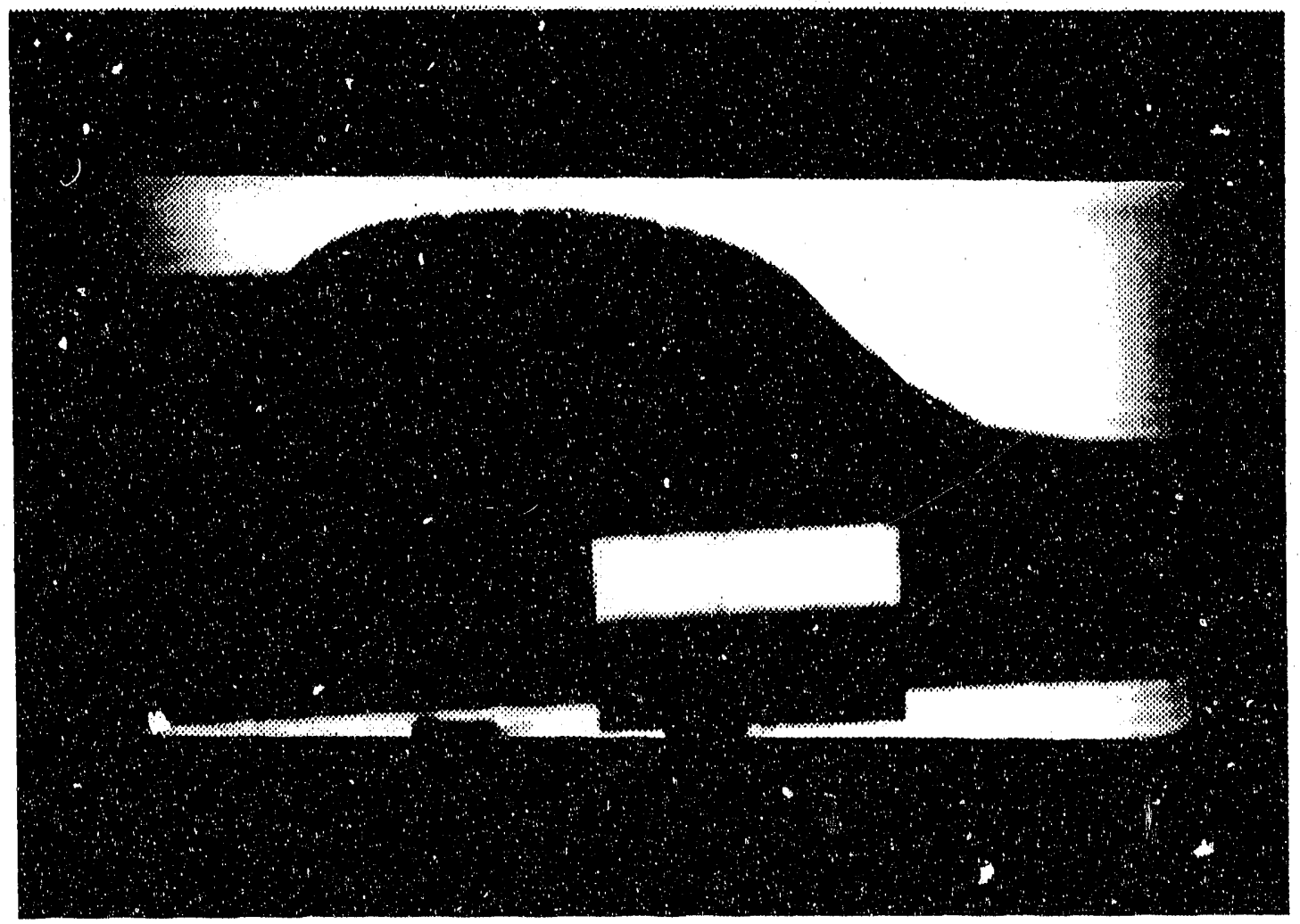

Figure 2. Sagittal MRI section of the lucite dog-head phantom.

Task 7B - Canine Treatment Planning and Posttreatment Evaluation:

A Labrador Retriever head has been obtained and will be dissected during the next reporting period to obtain more detailed anatomical and geometric detail than is currently utilized in the dog models used to support the BNL irradiations. Tissues will be sampled and analyzed to obtain better information on specific tissue compositions.

Because of BMRR unavailability no dogs were irradiated at BNL and no "treatment" calculations were performed during the reporting period. 
EGG-BNCT -8777

Vol. 4, No. 7

July, 1990

\section{PROJECT 2: LARGE ANIMAL MODEL STUDIES}

Spontaneously-Occurring Brain Tumor Studies: "Shorty" Morgan's (35447121) computed tomography (CT) and MRI scans showed an enhancing mass extending from the pituitary area. Shorty entered the terminal pharmacokinetic study, and received a three-hour boron infusion on July 2 . Results are pending.

"Gus" Apple (35447-122) was diagnosed as having a compression of the spinal cord at $\mathrm{C4}-5$ and removed from the project.

"Wulf" Lorenzen (35447-124) entered the project on July 2 and presented with head tilt to the left side, atrophy of head muscles, and lethargy. A CT scan revealed a mass in the left cerebellopontine area. He died of natural causes on July 11 and was necropsied. Results are pending.

"Kipnuk" Sutherland (35447-125) entered the pioject on July 11 . He presented with behavioral changes. No abnormalities were observed on cerebral spinal fluid (CSF) analysis or CT scan, He was euthanized on July 13, 1990. Results are pending.

"Beau" Smith (35447-126) entered the project on July 13. He presented with aimlessly wandering tendencies, listlessness, and lethargy. An intracranial mass was observed on CT and MRI scans. Because of his decreased health, he received a three-hour boron infusion, was euthanized, and necropsied. Results are pending.

"Sam" Warner (35447-127) entered the project on July 23. He presented with loss of equilibrium, staggering, head tilt to right, and shaking. Results of CT and MRI scans are pending, as are the remainder of test results.

"Niki" Fox (35447-128) entered the project on July 26. Niki presented with head tilt to right, ataxia and weakness in rear limbs, and seizures.

BNCT Treatment Studies: "Brandy" Gurdzinski (35447-093) is doing well and has no health problems. "Brandy" Hoff (35447-094) is also doing well. Her hair is starting to regrow with its normal color.

Normal Tissue Tolerance Studies: Dogs in the 10-Gy dose group are doing well. Blood parameters remain normal and no new skin lesions have developed. No neurological abnormalities have occurred. These dogs will be having their six-month rechecks, including CT and MRI SCans and CSF analysis, within the next week. 
EGG-BNCT-8777

Vol. 4 , No. 7

July, 1990

MR Spectroscopy: Two canine spectroscopy studies were performed on July 1. The dogs were received from WSU Junior Surgery and were returned after the spectroscopies.

Pharmacokinetics: Four Beagles have been received at WSU to complete the boron plasmapheresis studies. Two-hour boron plasmapheresis exchanges were performed on two of the dogs July 20 and 23. At the end of the procedure, the dogs were euthanized for tissue boron concentration analysis.

The latest information from large animal model experiments is summarized in Appendix A.

\section{PROJECT 3: HUMAN STUDIES}

This project is currently not funded.

\section{PROJECT 4: STABILITY, PHARMACOLOGY, AND TOXICOLOGY OF DRUGS}

This project is :urrently not funded.

\section{PROJECT 5: PBF TECHNICAL SUPPORT}

Design: The Preliminary Design Review for the core bismuth reflector/shielding and the lower core orifice plate was completed. Removing the stainless-steel, flow partition plate from the northeast quadrant of the core was also discussed during this review. This plate will not be required to prevent cross channeling when the filler elements are replaced with the reflector/shielding canisters. The Design Review Committee recommended the design presented be approved and final design is in progress.

An outstanding action item from the final design of the neutron filter and the neutron filter cooling system was to complete a Failure Mode and Effects Analysis (FMEA) of the systems as designed. This analysis will be 
$E G G-B N C T-8777$

Vol. 4, No. 7

July, 1990

used as input into the modification to the Safety Analysis Report for operation of PBF for BNCT. The EG\&G Probabilistic Risk Assessinent Unit started the FMEA during the reporting period.

Research into the applicable Federal and DOE requirements concerning patient safety fias started during the reporting period. These requirement.s will be used to develop design parameters for control of the reactor and shutter Hoors during irradiation. These requirements will also be used to define allowable limits for the safety analys is work scheduled to start near the begirning of $\mathrm{FY}-91$ and for the investigational device exempiion application planned for submittal to the Food and Drug Administration (FDA).

Analysis: The draft installation procedures for the neutron filter, reactor vessel nozzle, and the core support plate indicate a large amount of in-vessel work will be required. These installations will require draining the water from the reactor core to gain physical access. Gross and very conservative estimates have been made of the radiation levels expected in the reactor core witl. the fuel removed. These estimates must be refined in advance of beginning in-vessel work in order to plan events to limit the exposure of installation personnel to acceptable levels. A task to develop a strategy for characterizing the radiation levels in the reactor vessel was started during the reporting period. This task will result in a recommendation of lowering the vessel water level and making direct measuremenis, predicting radiation levels analytically, or some combination of both analysis and measurement.

\section{CORE A: ADMINISTRATION AND COMMON SUPPORT}

Program participants met with DOE-Energy Research (ER) on July 12 and presented the INEL rebuttal to the HERAC report.

BMRR: BMRR coritinues to be unavailable. The PBF/BNCT Program has five tumor dogs and 20 normal dogs awaiting irradiation at BMRR.

Dr. Patrick R. Gavin's (Project 2) request (to BNL) to increase the spontaneous, canine-brain-tumor dose tolerance study to include 20 additional dogs was disapproved. The basis for the decision was "lack of any peer review" and the DOE Health and Environmental Research Advisory Committee (HERAC) recommendation to concentrate on cell culture ard small animal studies. Dr. Gavin met with the BNL Institutional Animal Care and 
Use Committee (IAUC) on July 18 and disciussed the issues raised by HERAC. Approval to continue the normal dog-brain tolerance studies has been received.

Visitors: Dr. Gerald Maguire, Jr. (Department of Computer Science, Columbia University, NY) was invited to visit the INEL to discuss a possible solution to the medical image format issues facing the PBF/BNCT Program. A standard format is needed so the patient treatment planning system does not have to be able to translate all of the different formats used by various equipment manufacturers. Dr. Maguire is expected to be a valuable resource in this regard, since he has defined a standard format (subsequently adopted by the AAPM) and he has developed a number of translator programs to frocess the various manufacturer-specific formats.

Meetings, Conferences, etc.: A program paper entitled, "In-Vivo Chemical Shift Imaging of Canine Brain Tumors After Injection of $\mathrm{Na}_{2} \mathrm{~B}_{12} \mathrm{H}_{11} \mathrm{SH}$, " by $\mathrm{K}$. $M$. Bradshaw and T. L. Richards, has been selected for an oral presentation at the Society of Magnetic Resonance in Medicine to be held in New York City, NY on August 23, 1990.

Program participants met with European BNCT researchers at WSU on JuTy 13 14 to discuss collaboration between researchers in the ongoing WSU dog studies and in the planned European dog studies.

\section{Milestorie Status:}

\section{Milestone}

a. Complete Phase I: Acute Canine Radiation Tolerance Study

b. Revise BNCT Program Plan

c. Complete Noninvasive Boron Quantification Development for Clinical Use

d. Radiation Transport and Interaction Software Ready for Clinical Use

e. Complete Phase II: Acute Canine Radiation Tolerance Study

f. Complete Vessel Weld Mockup
Schedule

$6 / 90$

$9 / 90$

$10 / 90$

$3 / 91$

$9 / 91$

$9 / 91$
Actual

$6 / 27 / 90$

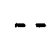

$-$

$-$ 
EGG-BNCT -8777

Vol. 4, No. 7

JuTy, 1990

\section{CORE B: PBF OPERATIONS}

Revision of the Plant Operating Manual (POM) to delete the nonapplicable sections and update those sections applicable to the PBF/3NCT Program continued through the month of July. All the draft changes have been completed and are in the internal review cycle.

The monthly, routine safaty walkthrough of the plant was completed for the month of July. Thase items identified during the walkthrough that can be corrected within the maintenance budget are being completed.

The scheduled preventive maintenance on the primary/secondary coolant system heat exchanger and cooling tower was deferred pending resolution for discharge of water to the corrosive waste pond. A meeting was held with the Consent Order Compliance Agency (COCA) representatives that determined there was no technical reason that discharge of water to the pond could not take place. Based on the results of this meeting, the secondary coolant system will be drained to the pond and the secondary preventive maintenances performed in August.

The scheduled preventive maintenance performed in the plant during the month of July included: (1) water mains and valves, (2) emergency generator, (3) diesel fire pump, (4) electrical fire pump, (5) fire extinguishers, (6) chemical treatment pumps, (7) auxiliary air compressor, (8) gas stack monitor, (9) plant air compressor, (10) constant air monitors, (11) $5 / 15$ ton overhead crane, and (12) exhaust fan.

Operations training conducted during the month of July consisted of:

(1) emergency action manual training for PBF personnel, (2) ethics training, and (3) satellite accumulation area and temporary accumulation area training for the environmental coordinator. 
EGG-BNCT - 8777

Vol. 4, No. 7

July, 1990

APPENDIX A

LARGE ANIMAL MODEL STUDIES

SUMMARY OF PATIENT DATA 

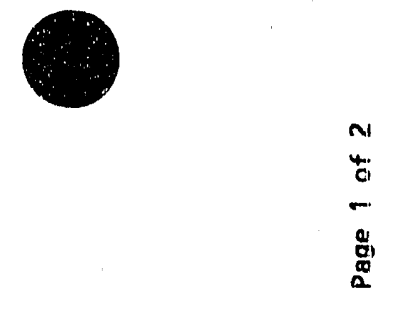

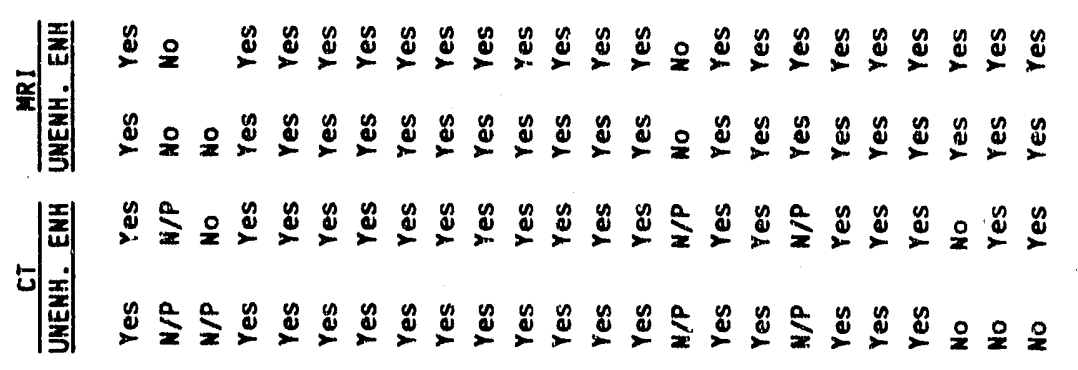

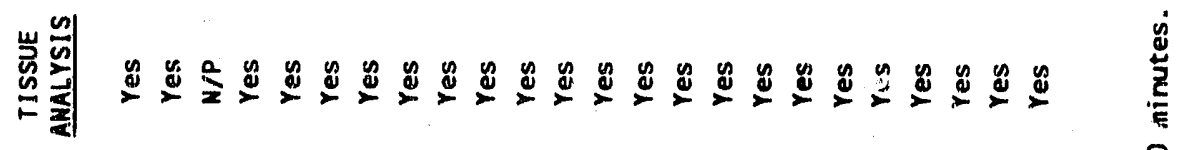

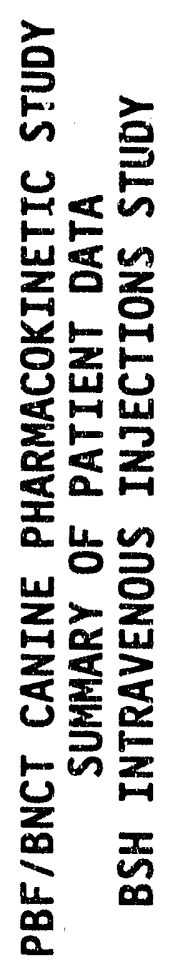

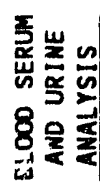

峞 \&

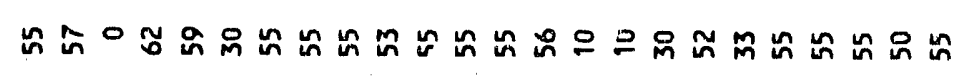

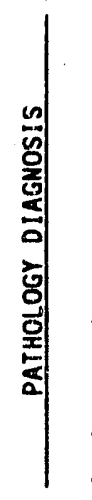

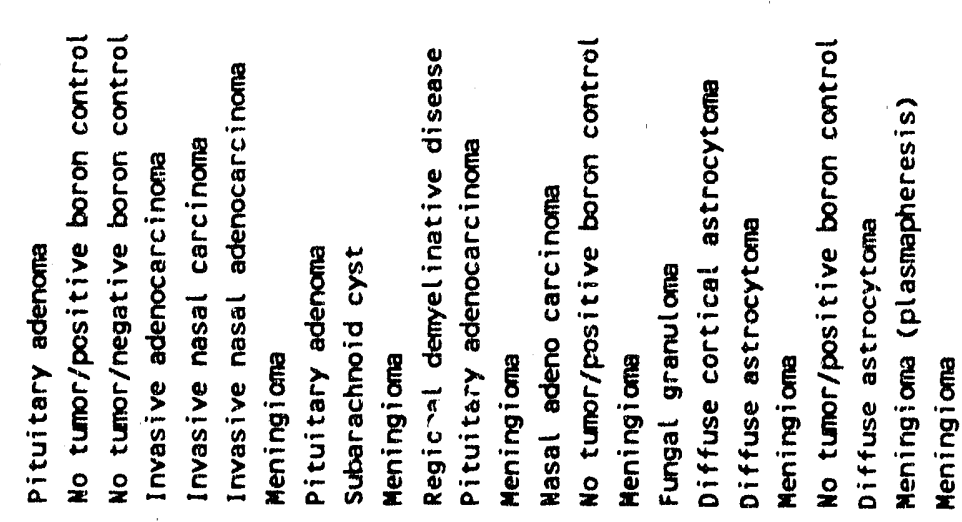

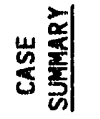

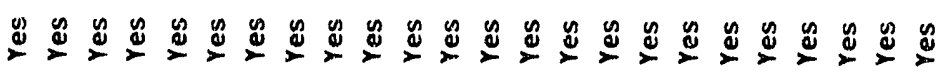
|

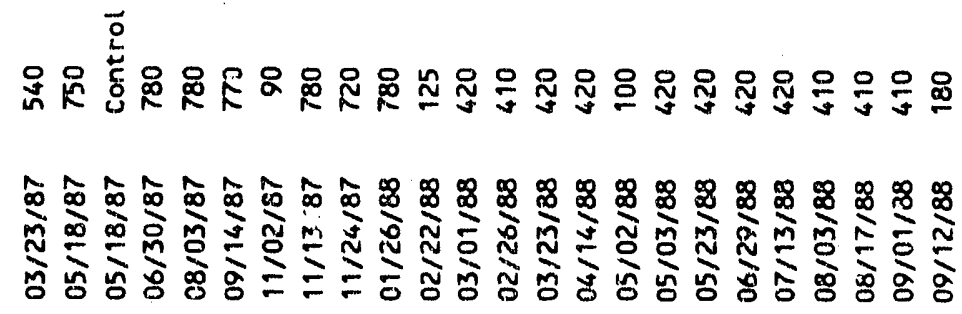

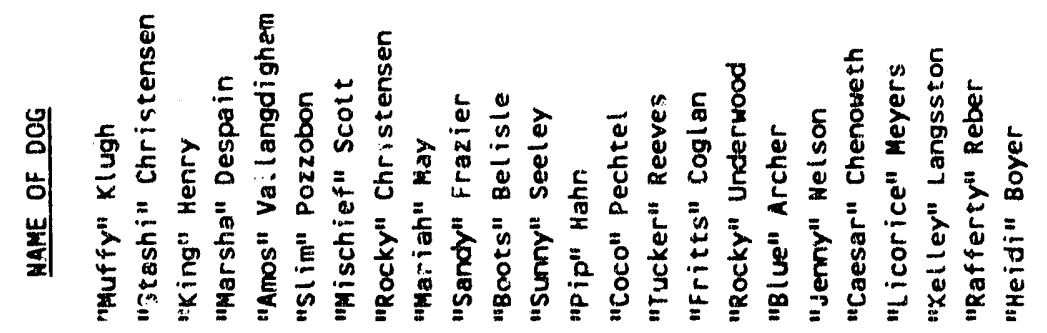

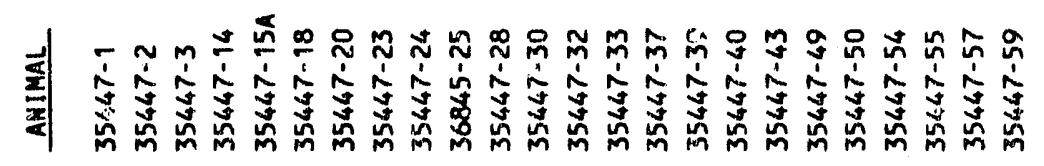

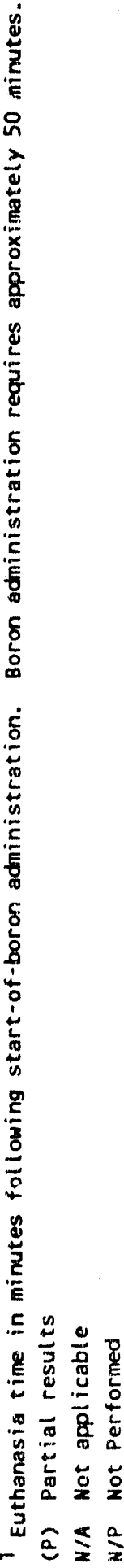



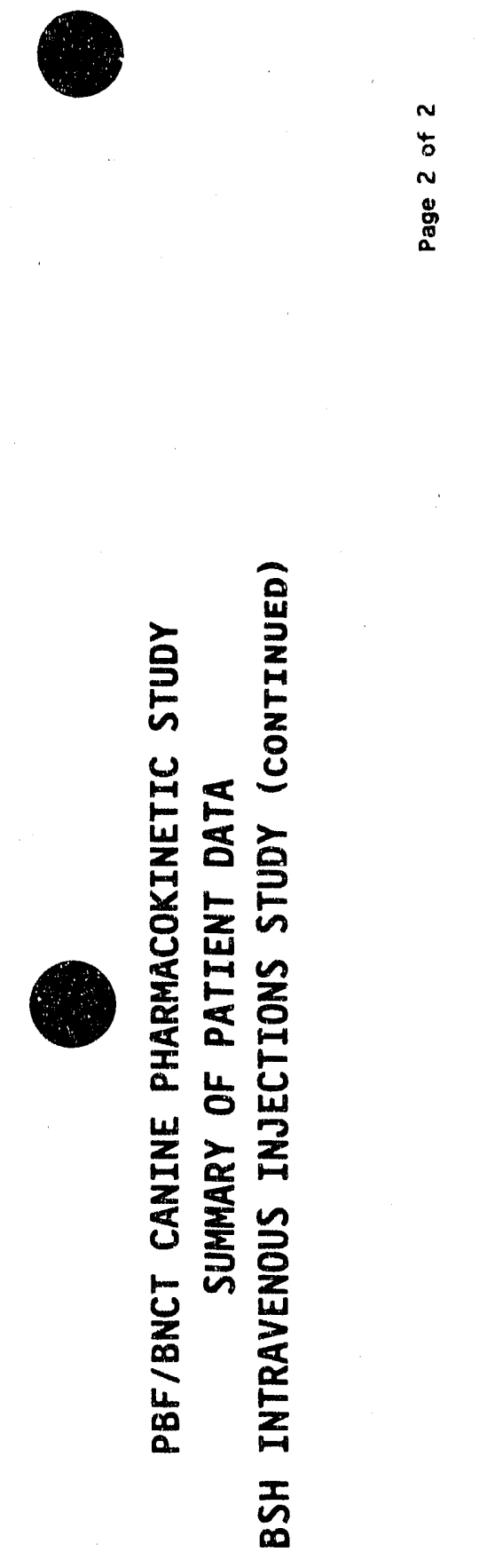

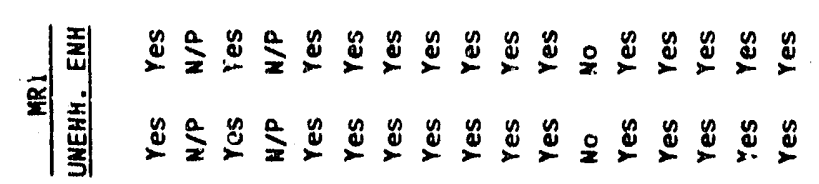

与ᄂ

\& \& 巳 \& \&

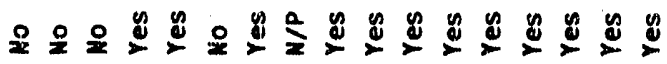

崫方章

원원 원

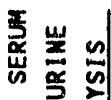

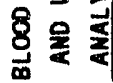

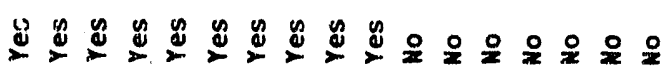

崖 着

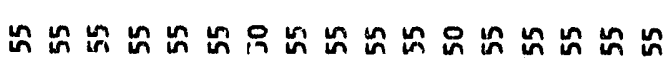
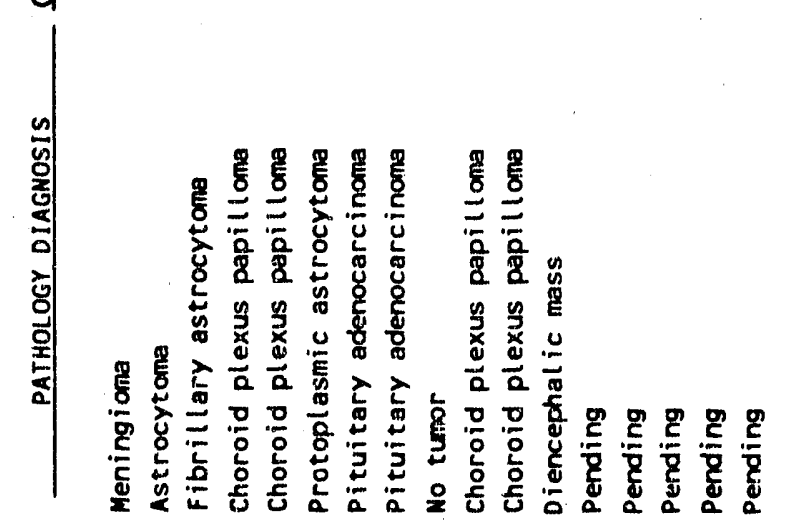

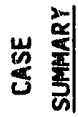

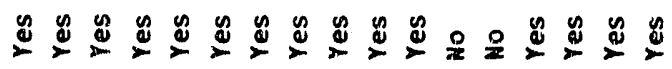

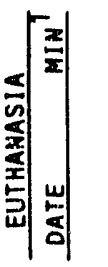

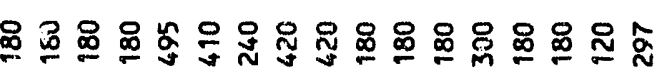

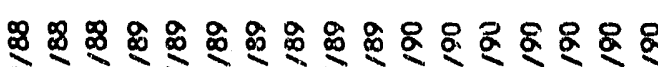

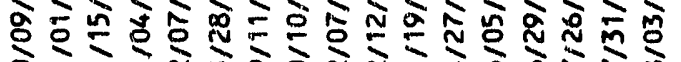

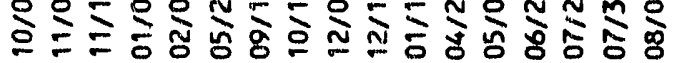

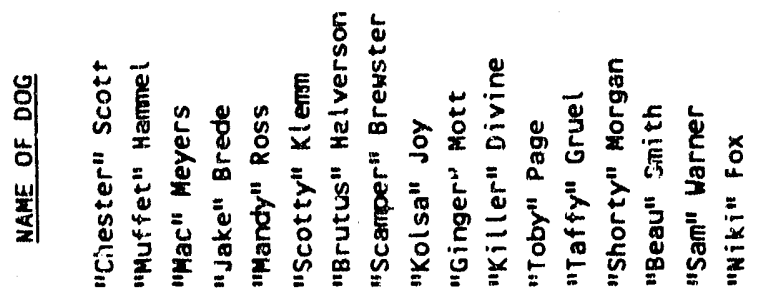

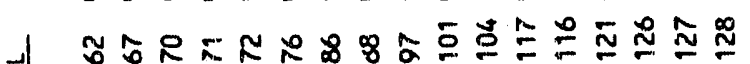

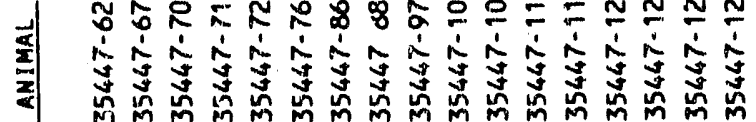


EGG-BNCT-8777

Vol. 4, No. 7

July, 1990

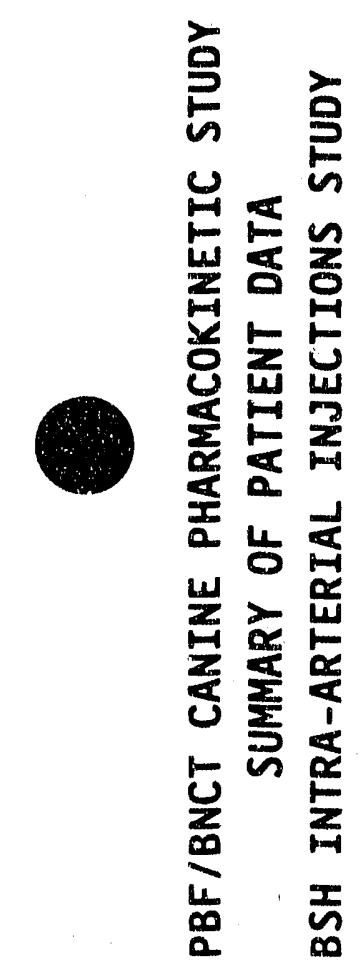

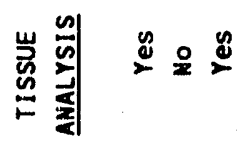
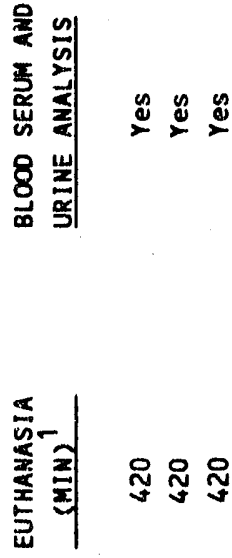

แ్

偬 $x u n$

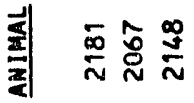




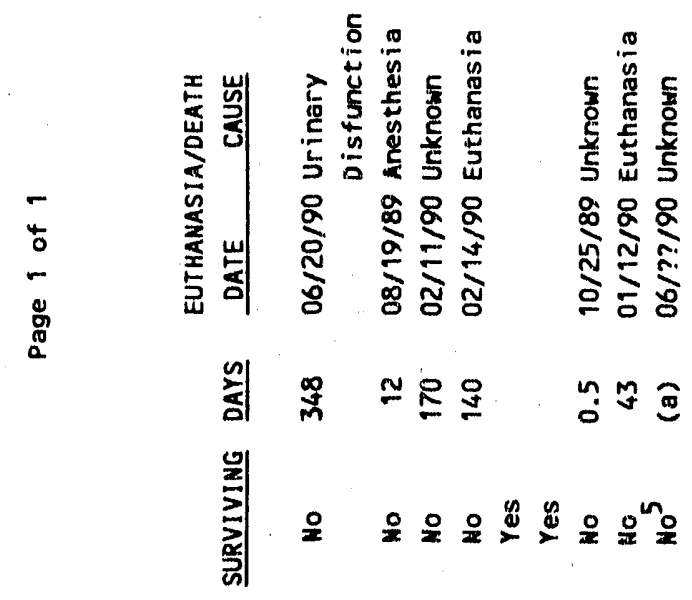

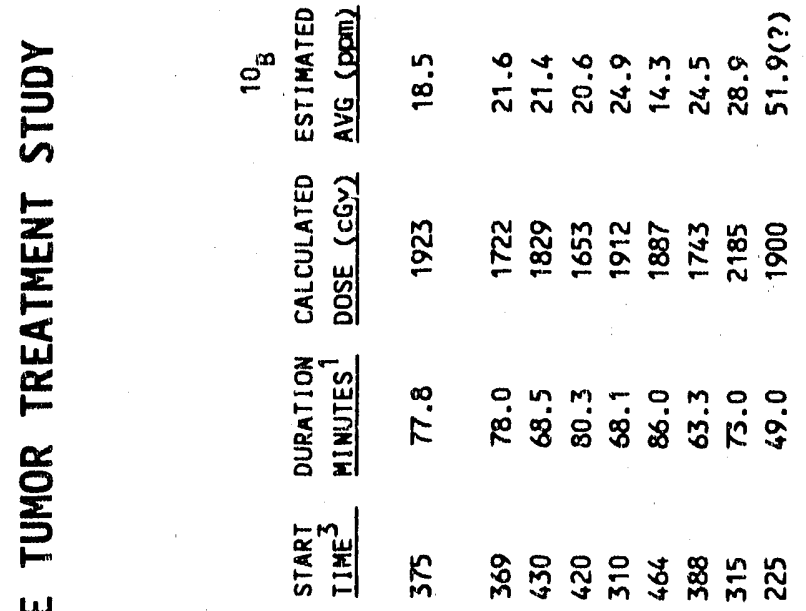

崖

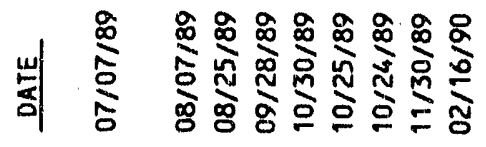

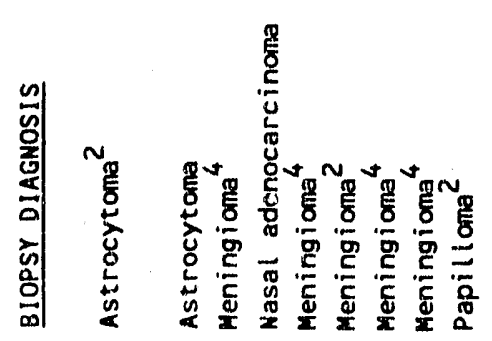

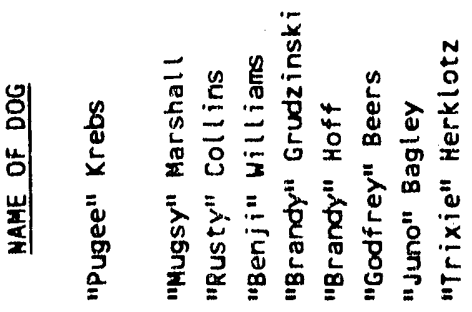

希 $4 \quad x \leq x 4 x 4$

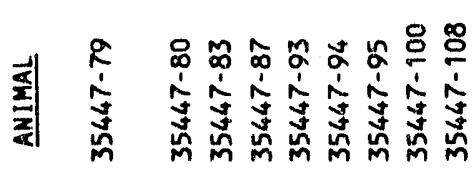

$\sum_{\substack{\text { L } \\ \text { co }}}^{5}$

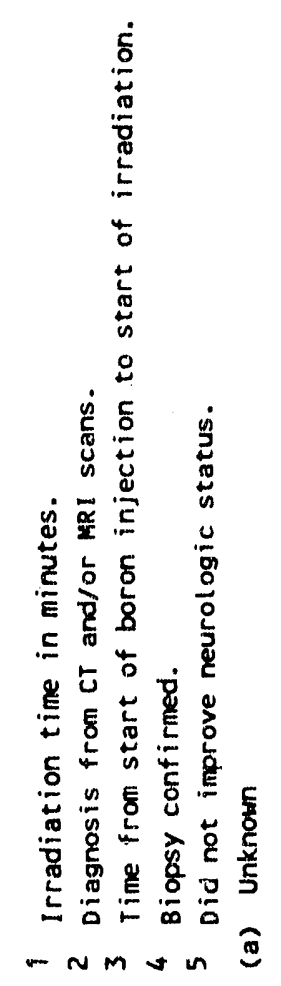


EGG-BNCT-8777

Vol. 4 , No. 7

July, 1990

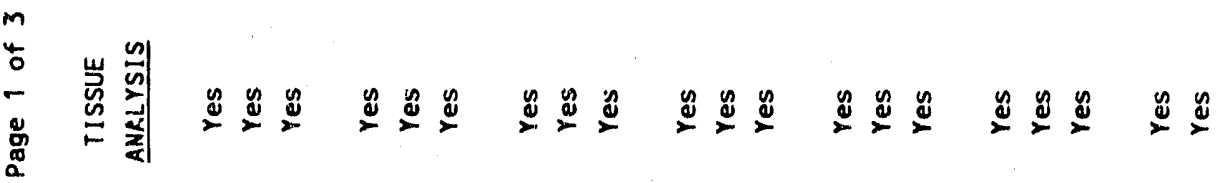

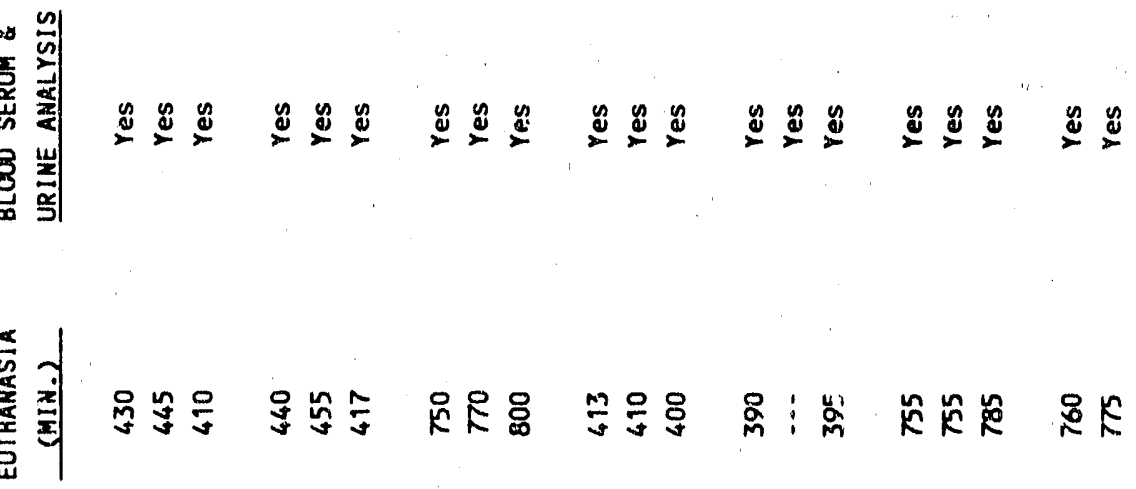

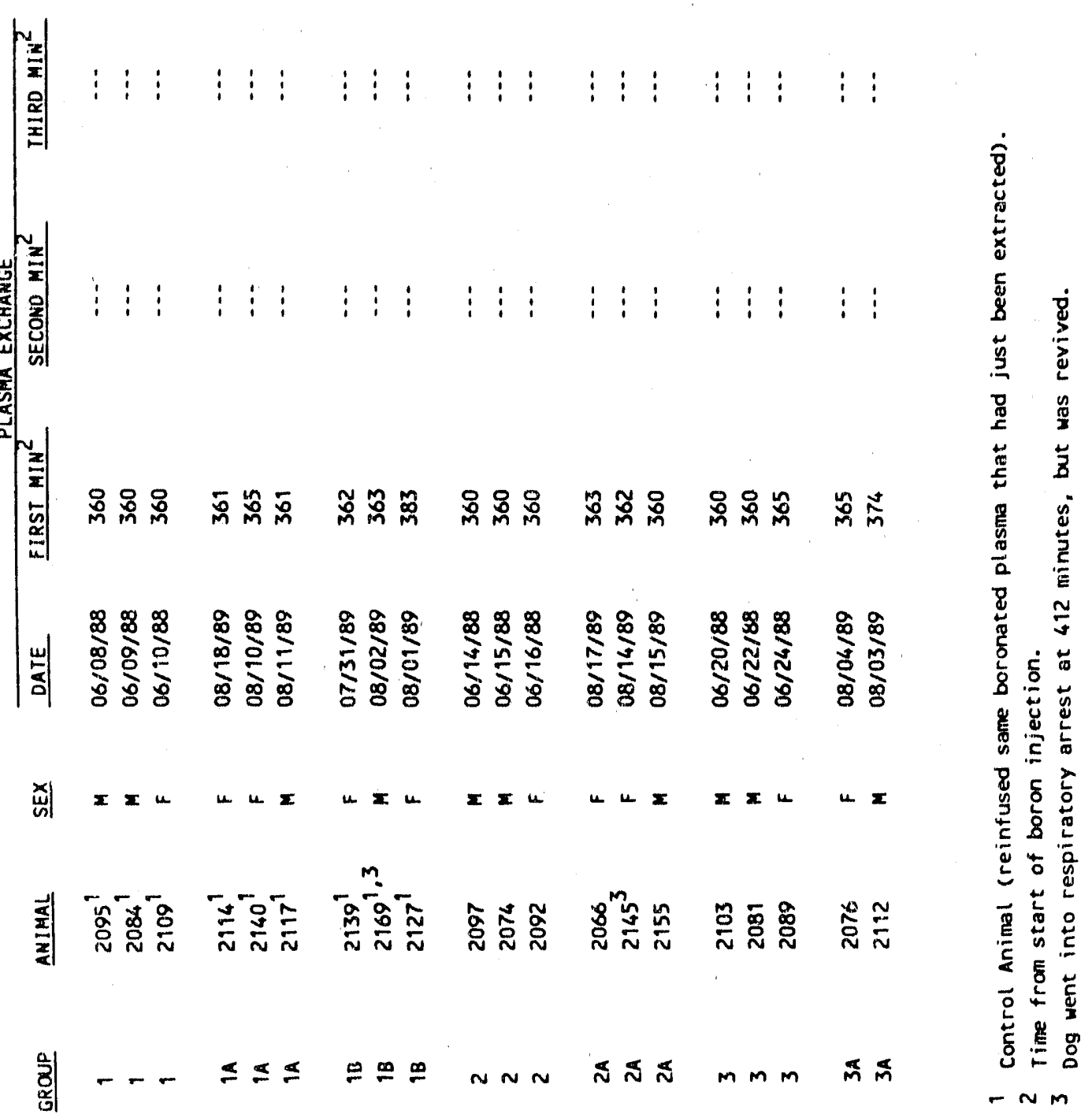




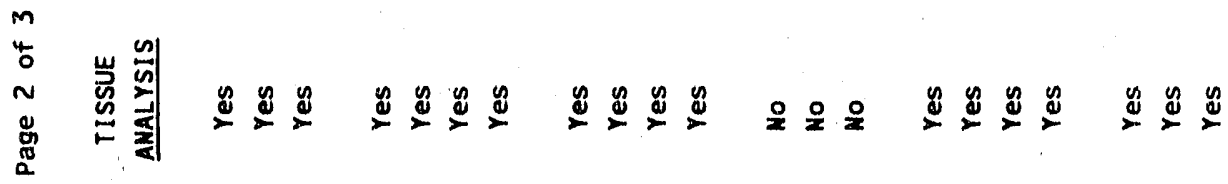

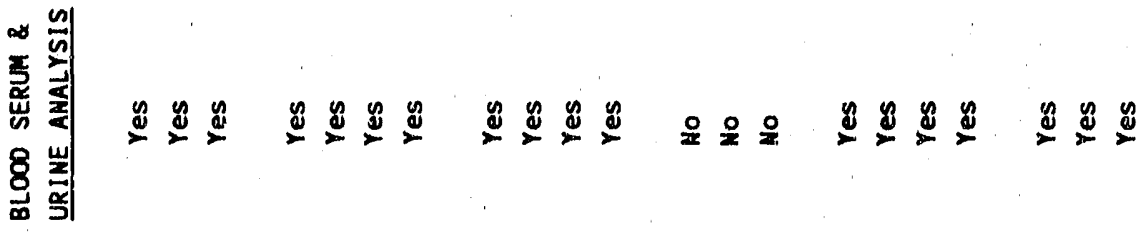

兽

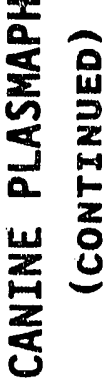

$\sum_{0}^{\infty}$

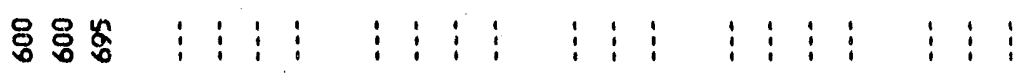

尽密出 : (1)

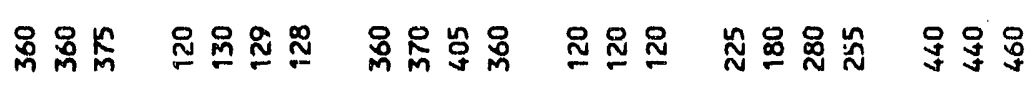

జి జ

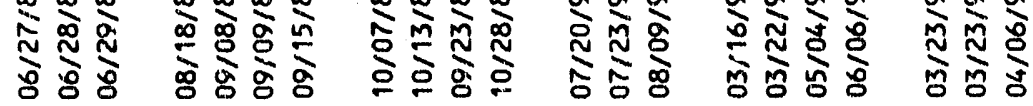

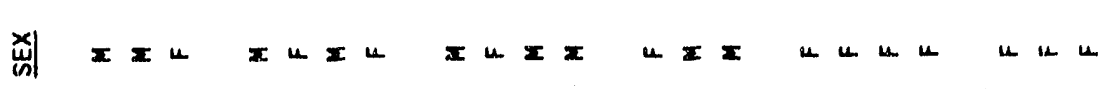

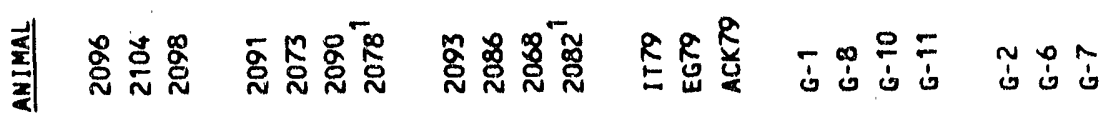

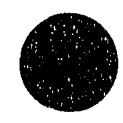

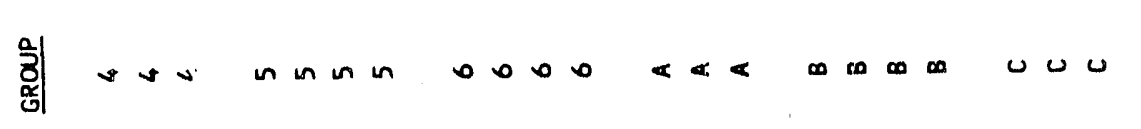


EGG-BNCT-8777

Vol. 4, No. 7

July, 1990

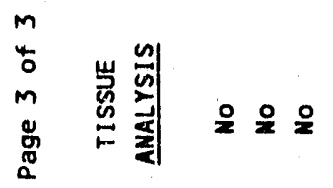

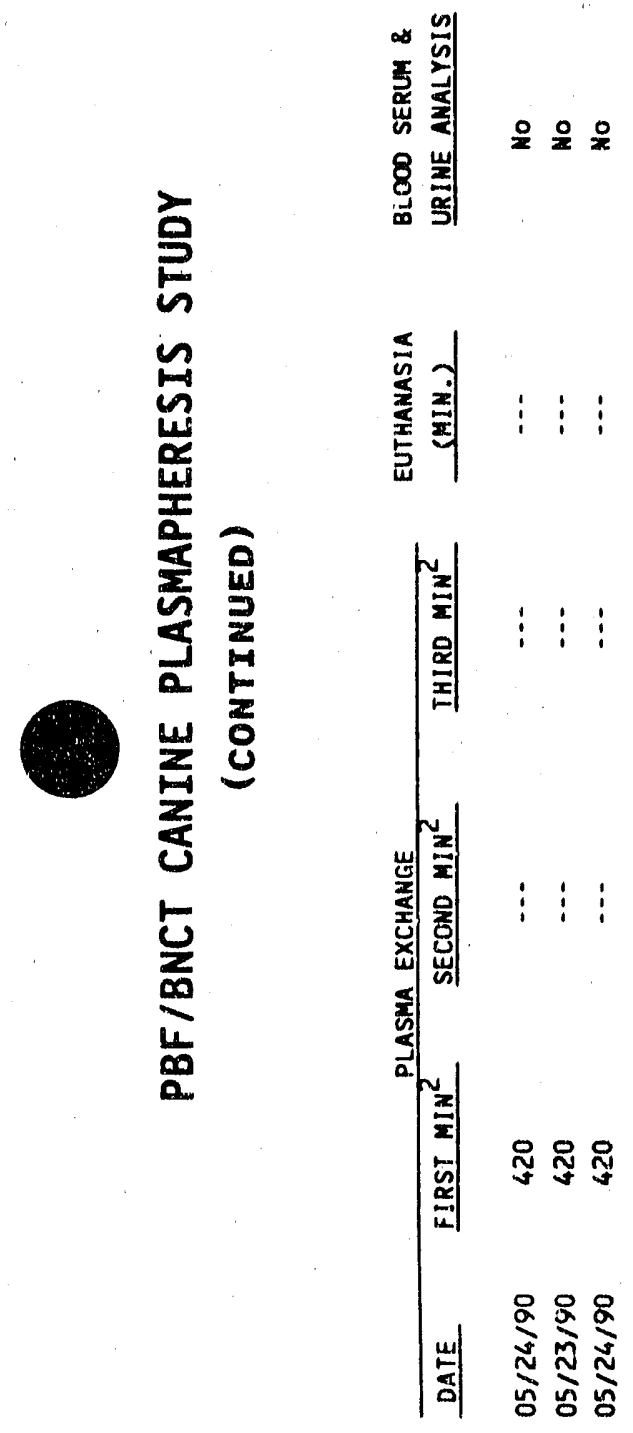

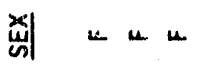

출 출

윙 * 눙

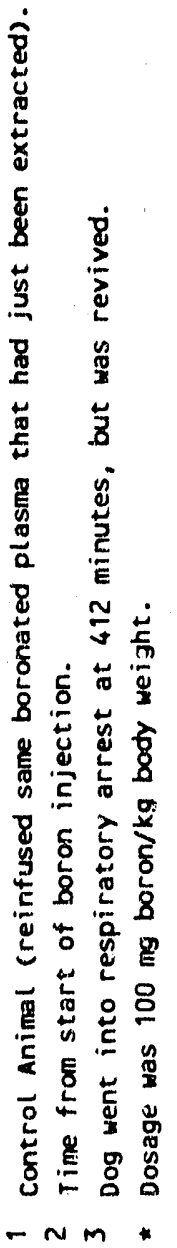




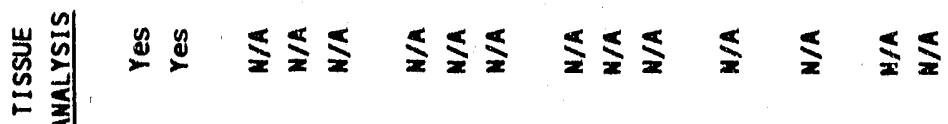

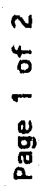

方

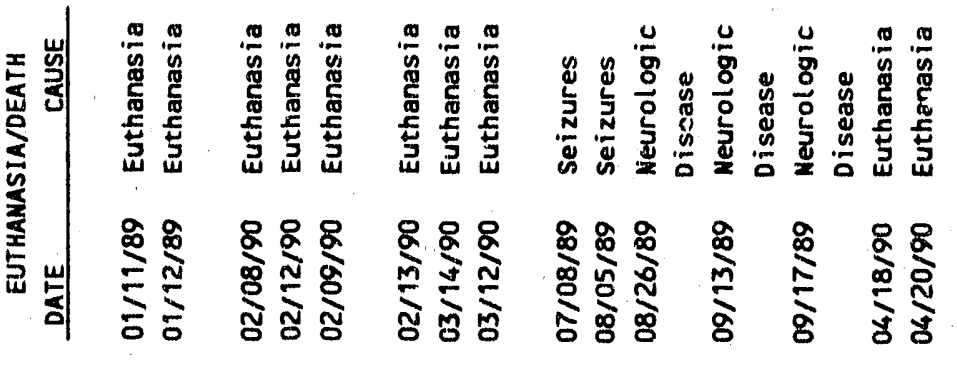

논

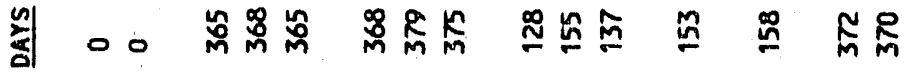

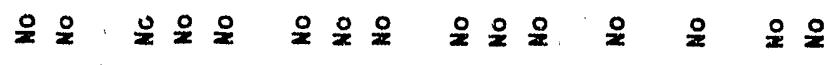

葸

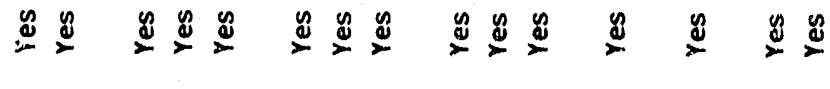

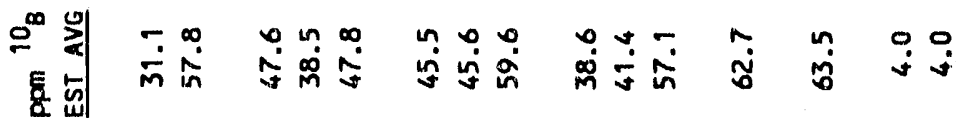

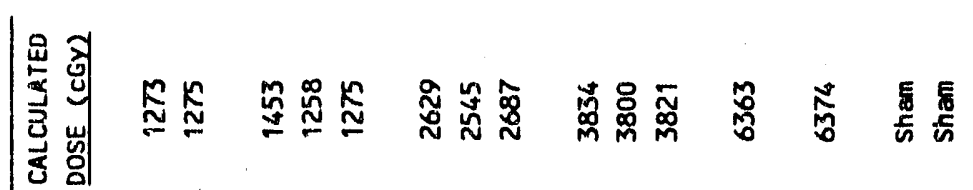

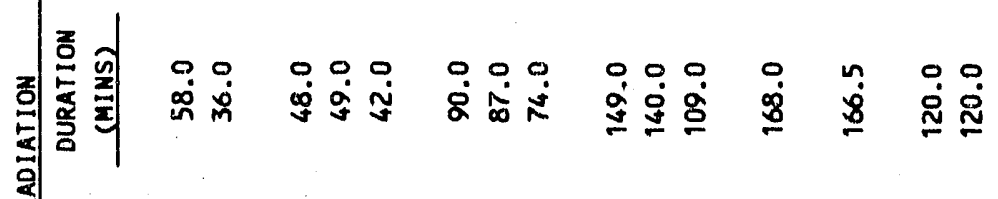

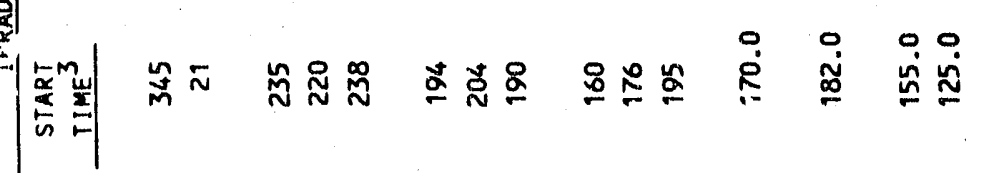

岸 希 $x x \leq x \leq x \leq x \leq x \leq x$

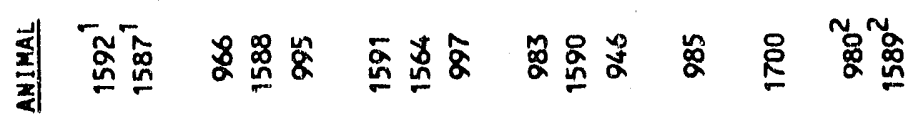

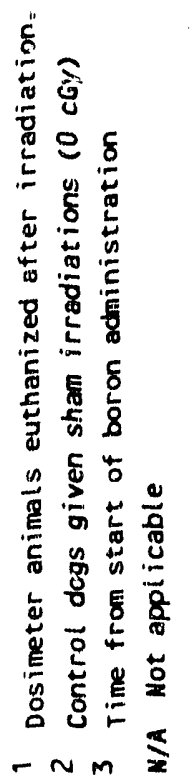


EGG-BNCT-8777

Vol. 4, No. 7

July, 1990
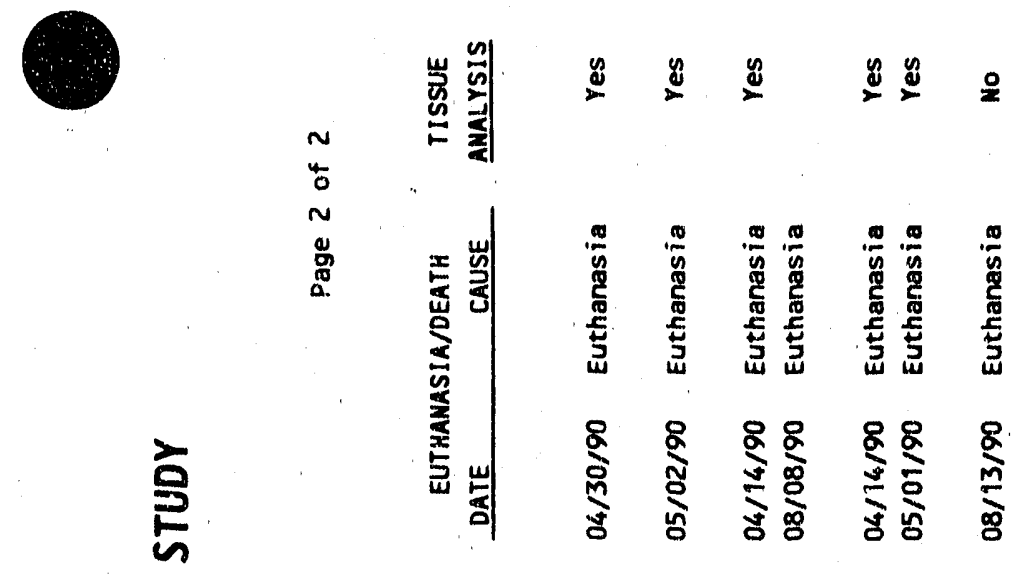

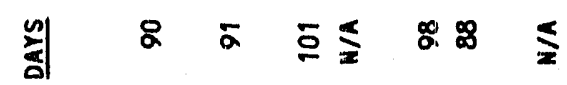

บ인

언 율

은 길

立

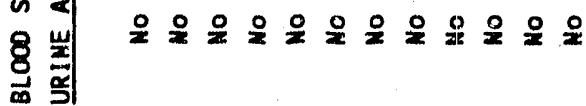

w

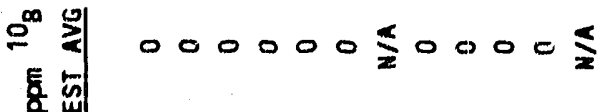

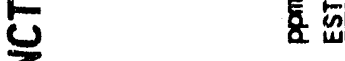

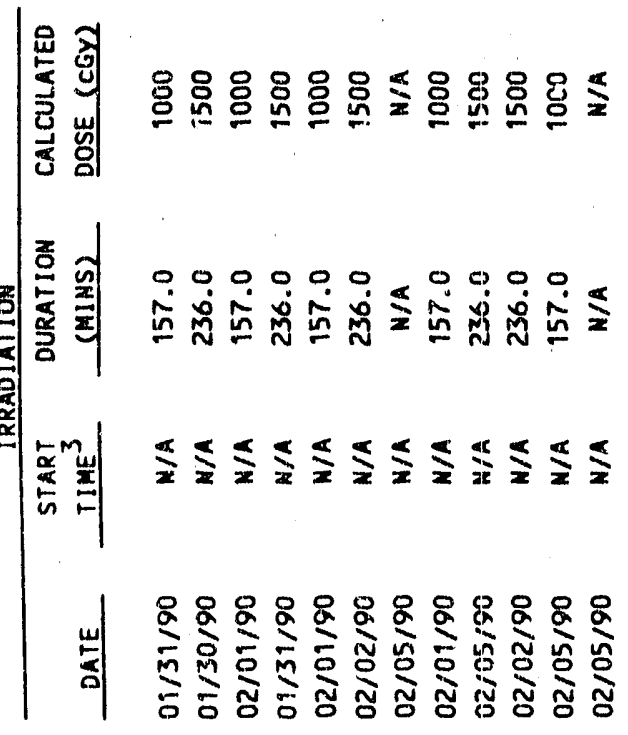

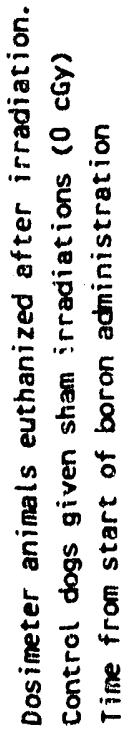

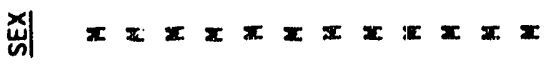

青 
EGG-BNCT-8777

Vol. 4, No. 7

July, 1990

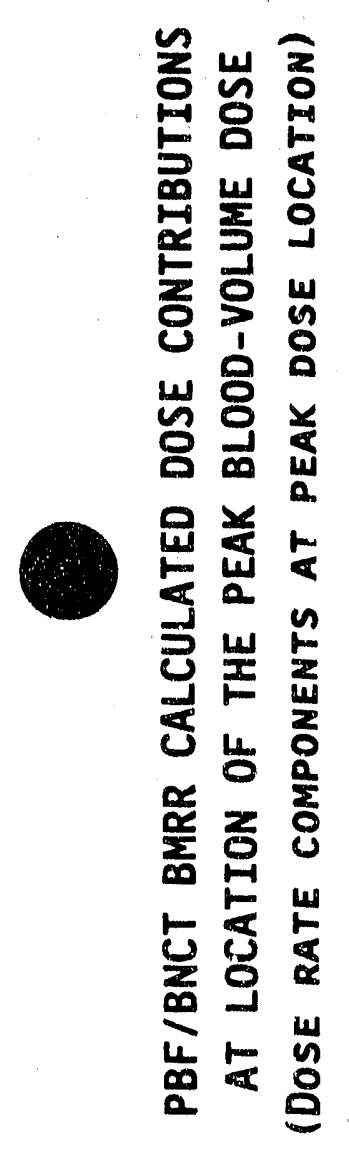

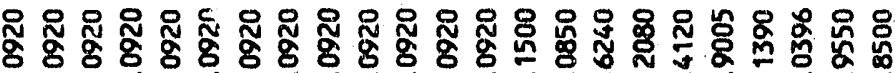

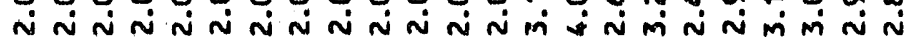

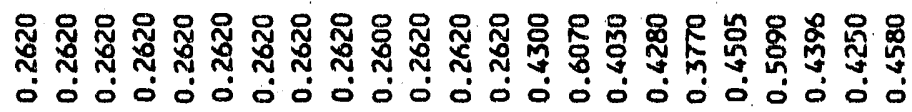

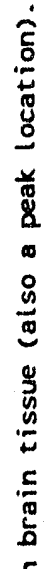

.

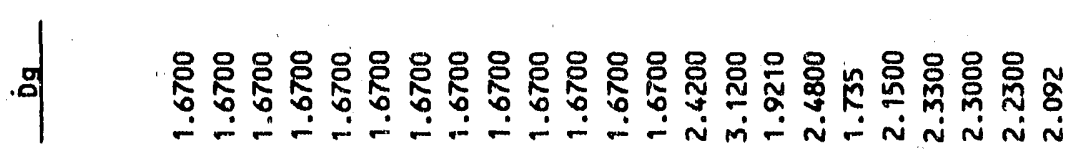

.5

$\mid$

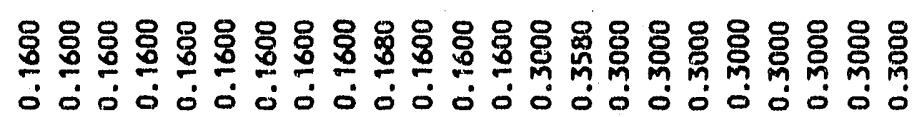

. คิ

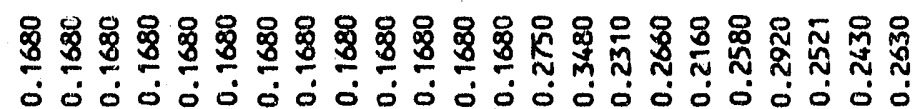

兽

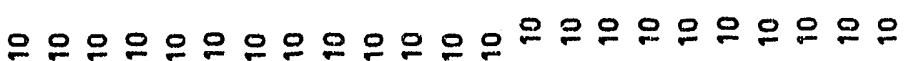
$x \times x \times x \times x \times x \times x \times x \times x \times x \times x \times x \times x$

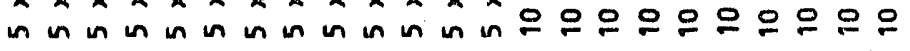

氙

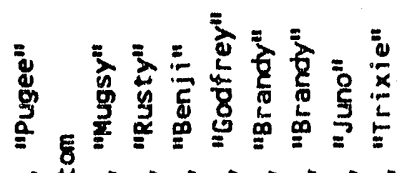

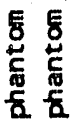

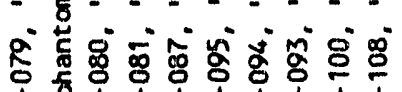

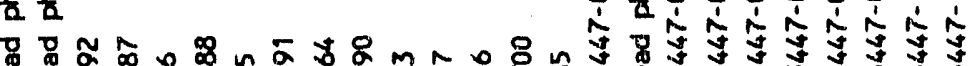

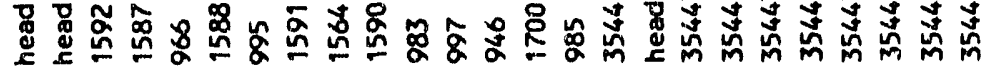

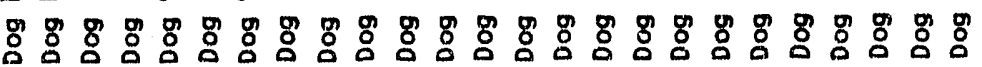

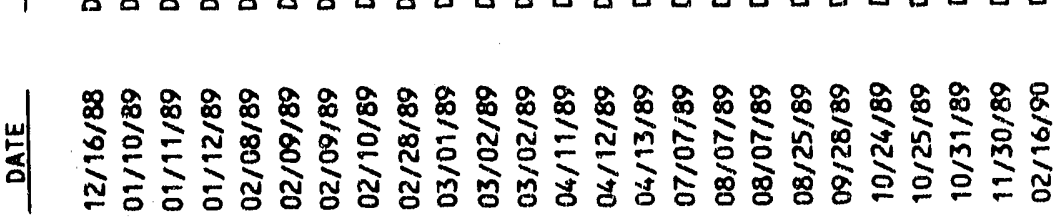




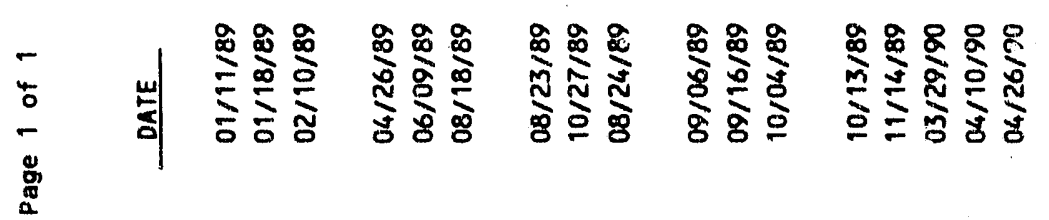

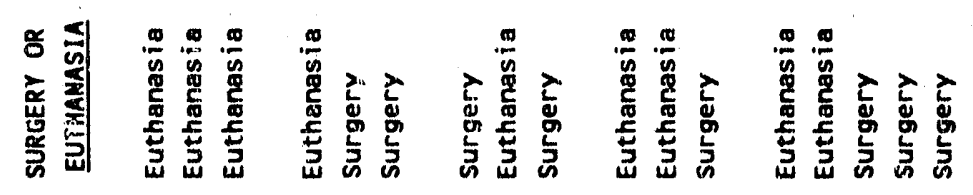

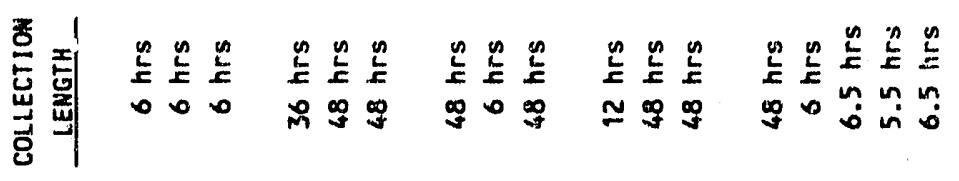

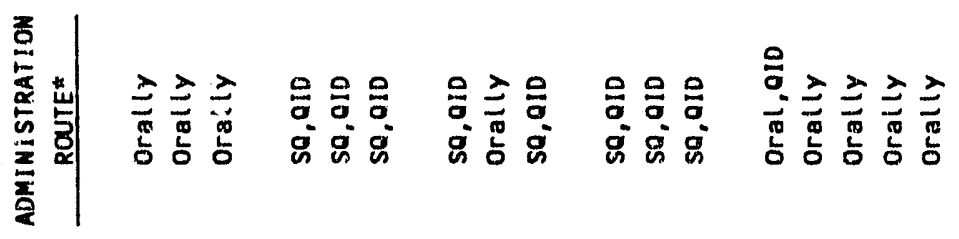

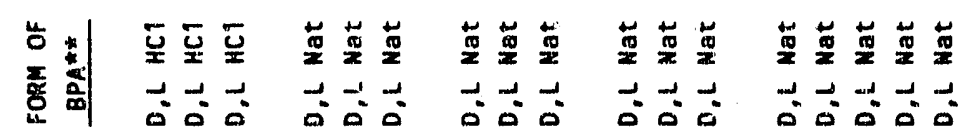

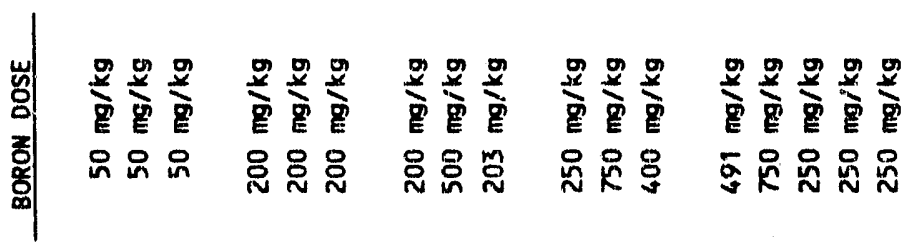

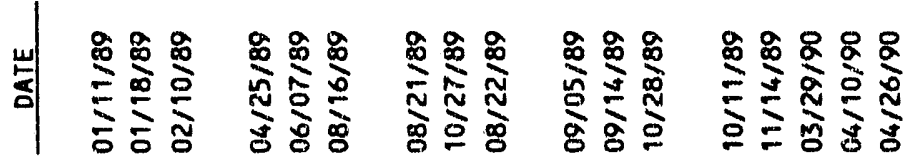

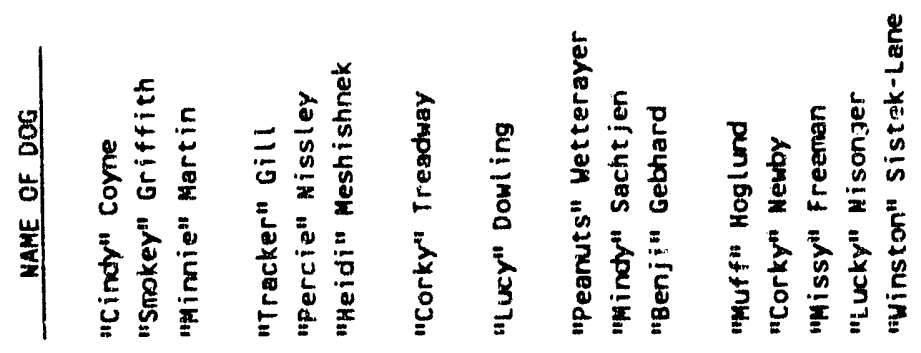

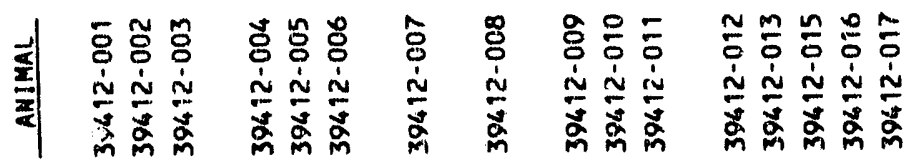

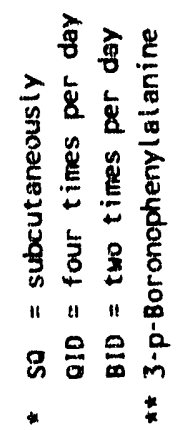



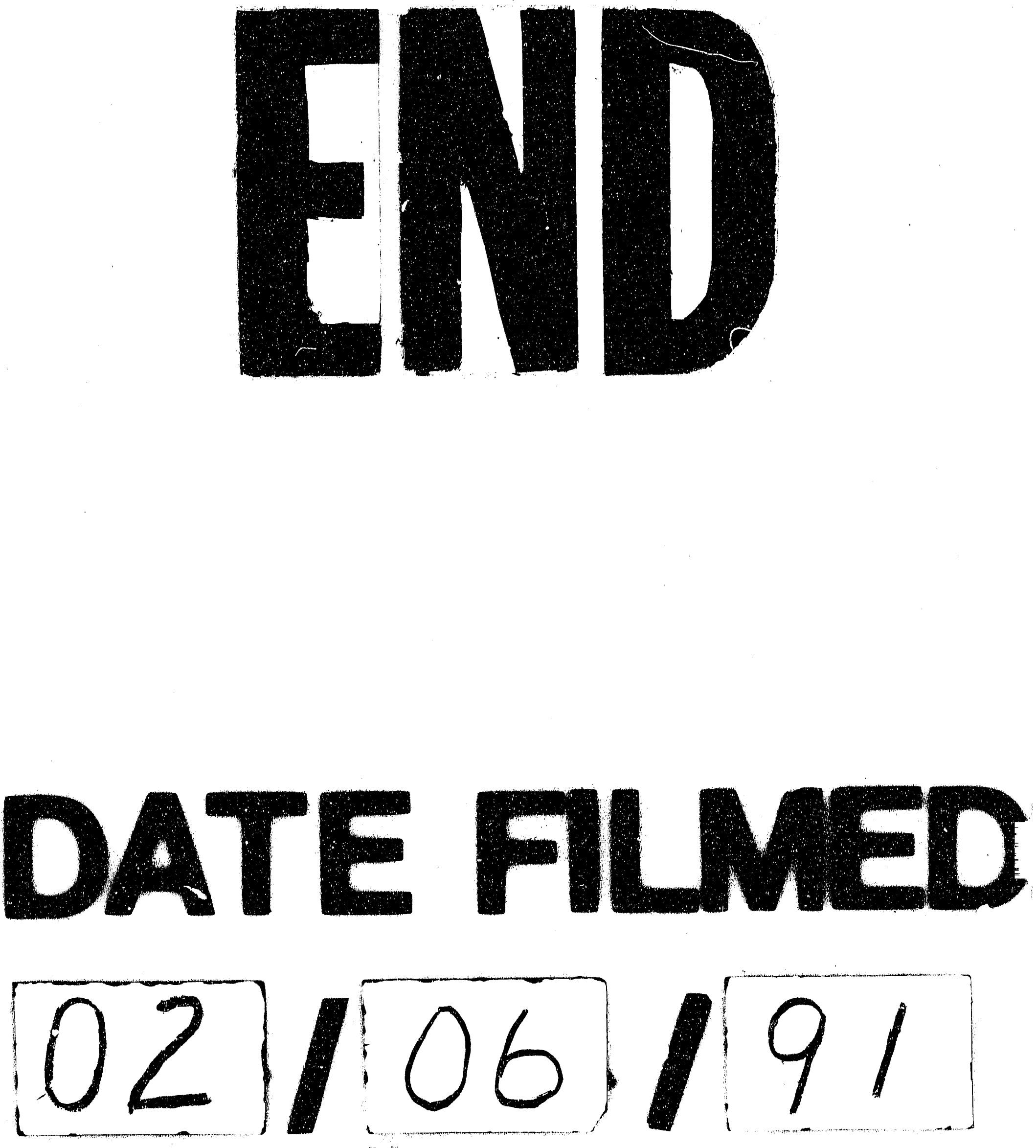
